\title{
IDENTIFYING THE POLY METHYL METHACRYLATE BEHAVIOR DURING FREE THERMOFORMING USING EXPERIMENTAL TESTS AND NUMERICAL SIMULATION
}

\author{
Mansour Sattarian, Aazam Ghassemi \\ Department of Mechanical Engineering, Najafabad Branch, Islamic Azad University, Najafabad, Iran and \\ Modern Manufacturing Technologies Research Center, Najafabad Branch, Islamic Azad University, Najafabad, Iran \\ e-mail:a_ghassemi@pmc.iaun.ac.ir;aazam77@yahoo.com
}

\begin{abstract}
Thermoforming is one of the new methods for forming of polymer sheets. Free thermoforming is one of the thermoforming methods in which shaping is done with air pressure or vacuum without the plug mold. In this paper, free thermoforming of Poly Methyl Methacrylate (PMMA) has been investigated by experimental tests and finite element simulation. The main purpose of this article is the identification of the real behavior of PMMA during free thermoforming to achieve maximum workable air pressure with respect to initial thickness. For this, at first, tensile and relaxation tests have been done in working temperature $\left(160^{\circ} \mathrm{C}\right)$. Then the process was simulated by Abaqus software with considering four types of the material property: three hyperelastic models (Ogden, Mooney-Rivlin, and Marlow) and a hyperviscoelastic model. After that, experimental tests were done, and the samples final shape were compared with simulation results. Accordingly, the simulation results obtained based on the Marlow hyperelastic model showed the best agreement with the experiments compared to others. After that, maximum workable air pressure versus plate initial thickness and minimum thickness of the deformed plate were achieved by finite element simulation.
\end{abstract}

Keywords: free thermoforming, Poly Methyl Methacrylate, hyperelastic, hyperviscoelastic

\section{Introduction}

The thermoforming process is one of the most popular techniques used in polymer processing. Thermoforming is used for fabricating lightweight, thin-walled products, and its largest application is in packaging. The required force for forming can be provided by air pressure, vacuum, plug mold or a combination of them. In order to perform the thermoforming process, the polymer sheet must be heated to a desired temperature above its glass transition temperature $T_{g}$, then positive or negative pressure is applied. Sometimes, for exerting high forces to the sheet, in addition of pressure, a plug load is required for proper forming or completion of the process. In the free thermoforming method, forming is done only by applying air pressure. For this process, at first, the sheet is clamped by a fixture, then the sheet is heated. After heating, the air pressure is applied and forming is done. This pressure remains until the sheet is cooled, so shrinkage is prevented (Throne, 1996).

In the free thermoforming process, there is no contact between the mold and the work piece. Thus the final surface of the products is smooth and perfect in comparison with other thermoforming methods. Usually, this method is used for manufacturing transparent products such as aircraft windshields (Throne, 1996).

Based on the study carried out by Han et al. (2013), simulation of thermoforming is a method to observe this process before running experimental tests. Furthermore, using ABAQUS software is an applicable method to simulate the behavior of hyperelastic materials (Ramezani et al., 2010; 
Shapourgan and Faraji, 2016). Bagherzadeh et al. (2010) used a cubic poly nominal model to predict hyperelastic behavior in the process of producing polyethylene terephthalate bottles.

There are some analytical, numerical and experimental studies on thermoforming of PMMA. Azdast et al. (2013) investigated thermoforming of a circular PMMA sheet by combination of free forming and plug-assisted forming. Also, they investigated final thickness of the sheet using a finite element model and experimental tests. They used the Mooney-Rivlin hyperelastic material model for simulation.

Wang et al. (2014) simulated high speed impact loading with aircraft windshields made of PMMA. For material properties, nonlinear viscoelastic model was used including the rate and temperature effects.

In another work, the critical material parameters of PMMA were investigated by Dong et al. (2005), where the uniaxial tension test was carried out in the range of 150 to $190^{\circ} \mathrm{C}$. They employed the hyperelastic Mooney-Rivlin and Ogden models and extracted coefficients of these models using the least square method. Using the results of this research, Dong et al. (2005) simulated the PMMA thermoforming at $160^{\circ} \mathrm{C}$. Moreover, thickness distribution of the sheet after deformation was analyzed (Dong et al., 2006).

Characterization of polymeric sheets can be determined by various tests (Bourgin et al., 1995; Schmidt and Carley, 1975a,b; Meissner et al., 1981; Meissner, 1987). Also, by classic uniaxial and equibiaxial tensile tests the same results can be obtained (Treloar, 1958; Alexander, 1968; Williams, 1970).

One of appropriate models in simulation of hyperelastic behavior of materials is the Marlow model when the uniaxial tensile test is available (Ghoreishy, 2012; Sharabi et al., 2016). Zafošnik et al. (2015) evaluated four types of hyperelastic models (i.e. Marlow, Ogden, NeoHookean and Yeoh) to simulate hyperelastic behavior in which the Marlow model was the best. In another work, Mahl et al. (2016) used the Marlow model in order to predict hyperelastic behavior of polyethylene in ABAQUS software. They claimed that the simulated results were in good agreement with experimental ones. To simulate hyperelastic behavior of rubber compounds, Ghoreishy (2012) implemented the Marlow, Ogden, Yeoh and Polynomial models where the best response was related to the Marlow model.

In most of researches, in simulation of yje PMMA thermoforming process, the material has been considered hyperelastic, especially obeying the Moony-Rivlin and Ogden models.

In this article, free thermoforming of PMMA is simulated by Abaqus software with considering four types of material propertyies: three hyperplastic models (Ogden, Mooney-Rivlin, and Marlow) and a hyperviscoelastic model. Uniaxial and relaxation tests have been done at the working temperature $\left(160^{\circ} \mathrm{C}\right)$ for extracting coefficients of the models. Then, the minimum thickness and maximum deflection of the simulated plate were compared with experimental tests. This comparison can determine the best model for simulation of PMMA free thermoforming at $160^{\circ} \mathrm{C}$. By finite element simulation of the best model, the purpose of the article, that is the identification of the real behavior of PMMA during free thermoforming to achieve maximum workable air pressure with respect to initial thickness, can be achieved.

\section{Hyperelastic material constitutive equations}

Hyperelastics are nonlinear materials that show elastic behavior even in very large deformations. The constitutive equation of such materials is usually expressed by using strain energy function $U$. The stress and strain relation is as below

$$
S_{i j}=\frac{\partial U}{\partial E_{i j}}
$$


Usually, $U$ is written as a power series (Treloar, 1958)

$$
U=\sum_{i=0}^{M} \sum_{j=0}^{N} A_{i j}\left(I_{1}-3\right)^{i}\left(I_{2}-3\right)^{j}
$$

In this relation, $A_{i j}$ are constants of the material, and $I_{1}, I_{2}$ and $I_{3}$ are deviatory strain invariants that can be calculated as below

$$
I_{1}=\lambda_{1}^{2}+\lambda_{2}^{2}+\lambda_{3}^{2} \quad I_{2}=\lambda_{1}^{2} \lambda_{2}^{2}+\lambda_{2}^{2} \lambda_{3}^{2}+\lambda_{1}^{2} \lambda_{3}^{2} \quad I_{3}=\lambda_{1} \lambda_{2} \lambda_{3}
$$

In equations (2.3), $\lambda_{1}, \lambda_{2}$ and $\lambda_{3}$ are principal stretches for incompressible hyperelastic materials

$$
\lambda_{1} \lambda_{2} \lambda_{3}=1
$$

\subsection{General strain energy functions for PMMA}

In this article, three types of strain energy functions have been investigated for simulating free thermoforming of PMMA. In this Section, these functions are given in brief.

\subsubsection{Mooney-Rivlin hyperelastic model}

This model is suitable for incompressible materials that show elastic behavior up to 200 percent of elongation (Milani and Milani, 2012). The strain energy function for this model is

$$
U=C_{10}\left(I_{1}-3\right)+C_{01}\left(I_{2}-3\right)
$$

In Eq. (2.5), $C_{10}$ and $C_{01}$ are material constants (Simulia, 2012).

\subsubsection{Ogden hyperelastic model}

This model is appropriate for incompressible materials that show elastic behavior up to 700 percent of elongation (Treloar, 1958). The strain energy function for this model is

$$
U=\sum_{i=1}^{N} \frac{2 \mu_{i}}{\alpha_{i}^{2}}\left(\lambda_{1}^{\alpha_{i}}+\lambda_{2}^{\alpha_{i}}+\lambda_{3}^{\alpha_{i}}-3\right)
$$

where $\alpha_{i}$ and $\mu_{i}$ are material constants achieved through experimental tests (Simulia, 2012).

\subsubsection{Marlow hyperelastic model}

In this model, the strain energy function is divided into volumetric and deviatoric parts

$$
U=U_{\text {dev }}\left(I_{1}\right)+U_{v o l}\left(J^{e I}\right)
$$

where $U$ is the strain energy per unit of the reference volume, with $U_{d e v}$ as its deviatoric part and $U_{v o l}$ as its volumetric part; $I_{1}$ is the first deviatoric strain invariant and $J^{e I}$ is the elastic volume ratio (Simulia, 2012).

\section{Viscoelastic materials}

Viscoelasticity is behavior between full terms of elasticity and viscosity. The material property of viscoelastic materials depends on time and history of deformation.

Regarding the temperature of deformation, the material property of polymers changes between two ideal types of behavior: elastic and viscous. 


\subsection{Prony series model}

Many models have been proposed for simulation of viscoelastic materials such as the Maxwell, Kelvin, etc. Several Kelvin models in series or several Maxwell models in parallel make the Prony series model. On the contrary to the Maxwell and Kelvin models, the Prony series model has several relaxation times in addition of not having disadvantages because of them. The Prony series model is suitable for processes with short times such as thermoforming. Figure 1 shows the Prony series model made by several Kelvin models in series (Marques and Creus, 2012).

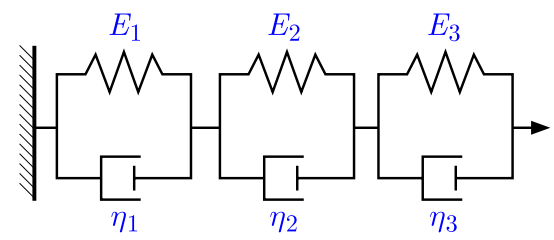

Fig. 1. Prony series model made by several Kelvin models in series

The normalized shear modulus $g_{N}(t)$ of the Prony series model is as follow

$$
g_{N}(t)=1-\sum_{i=1}^{N} g_{i}\left(1-\mathrm{e}^{\frac{-t}{\tau_{i}}}\right)
$$

In this equation, $g_{i}$ and $\tau_{i}$ are material constants obtained by a relaxation test (Simulia, 2012).

\section{Simulation of the PMMA free thermoforming process}

PMMA is a transparent thermoplastic polymer. Its material properties are significantly dependent on temperature and rate of deformation. Excellent optical quality, high ductility, high resistance against various weather conditions, high impact strength and low shrinkage are the most important properties of PMMA (Alobaidani et al., 2010). In this paper, free thermoforming of PMMA (Mil-P-8184 grade) is investigated at $160^{\circ} \mathrm{C}$. For proper simulation, the most important problem is the selection of the material property. To extract the constant values of hyperelastic and hyperviscoelastic models in simulation, a uniaxial tensile test coupled with a relaxation test was carried out on prepared samples at $160^{\circ} \mathrm{C}$.

\subsection{Tension and relaxation tests}

For representing hyperelastic properties of PMMA (Mil-P-8184 grade), a uniaxial tensile test was done at the working temperature. For this purpose, samples have been prepared according to ASTM D638 standard test (D-638 Standard, 2004). Figure 2 shows the sample dimensions.

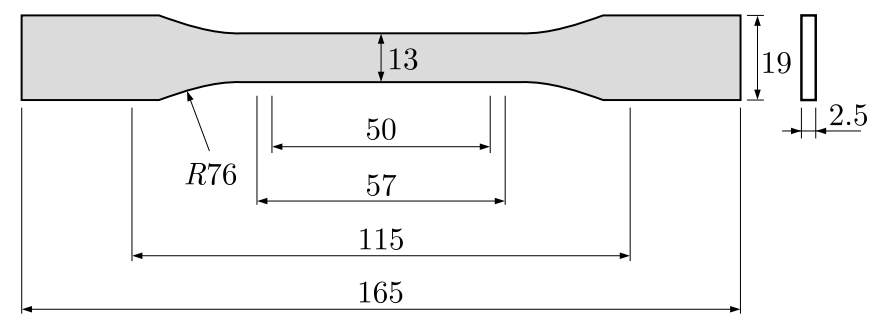

Fig. 2. Sample dimensions according to ASTM D638 standard test

The stress-strain curve was obtained from tensile test at $160^{\circ} \mathrm{C}$. For reliability of the test, it was repeated 5 times, and the average is shown in Fig. 3. 


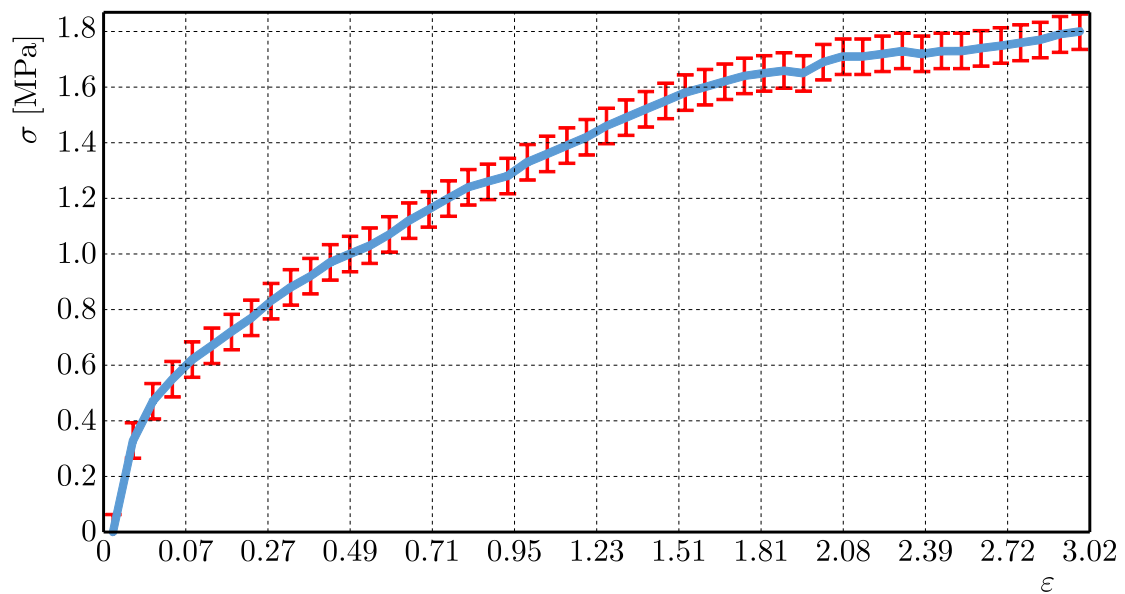

Fig. 3. PMMA (Mil-P-8184 grade) stress-strain curve, at $160^{\circ} \mathrm{C}$, in a uniaxial tension test

To determine the viscoelastic behavior of this material, a relaxation test was carried out at $160^{\circ} \mathrm{C}$. Figure 4 illustrates the force decreasing with time. For reliability of the test, it was repeated 5 times, and the average is shown in Fig. 4.

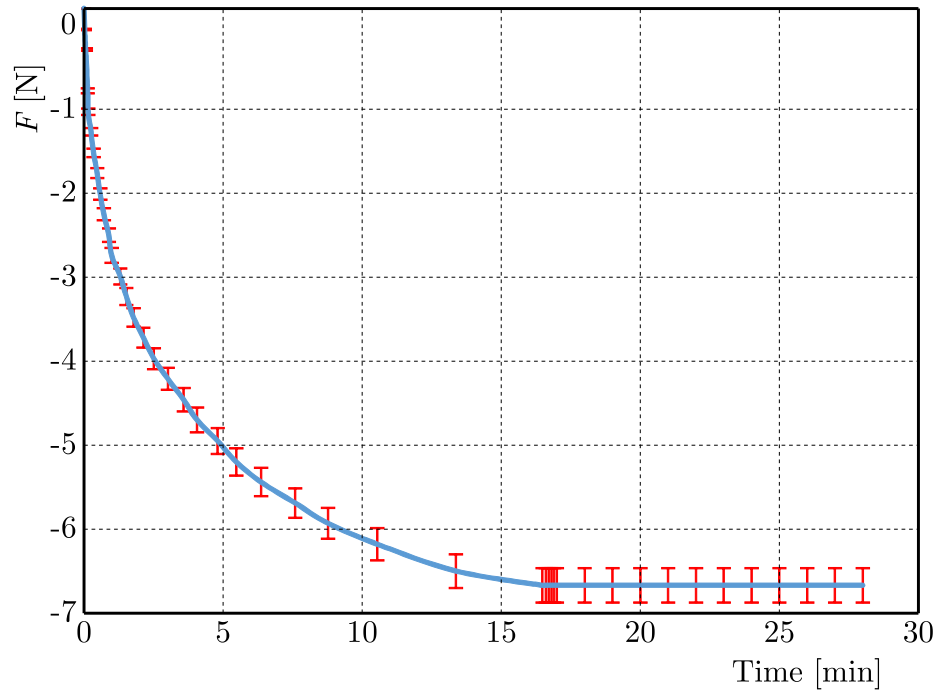

Fig. 4. Force-time curve obtained from the relaxation test

\subsection{Hyperelastic model}

From the uniaxial tension test data (Fig. 4), material constants of strain energy models can be obtained by the least square method. Using the property module of Abaqus software, usual strain energy models, suitable for PMMA, were evaluated (Fig. 5). As it can be seen, the Marlow model is matched with the achieved test data.

Material constants are shown in Table 1.

Table 1. Material constants in hyperelastic models

\begin{tabular}{|c|c|}
\hline \multicolumn{2}{|c|}{ Hyperelasticity - Mooney-Rivlin strain energy } \\
\hline$C_{10}=-431089.434$ & $\overline{C_{01}=1465380.54}$ \\
\hline relasticity & fi \\
\hline$\mu_{i}=1626755.10$ & $\alpha_{i}=-2.34531635$ \\
\hline
\end{tabular}




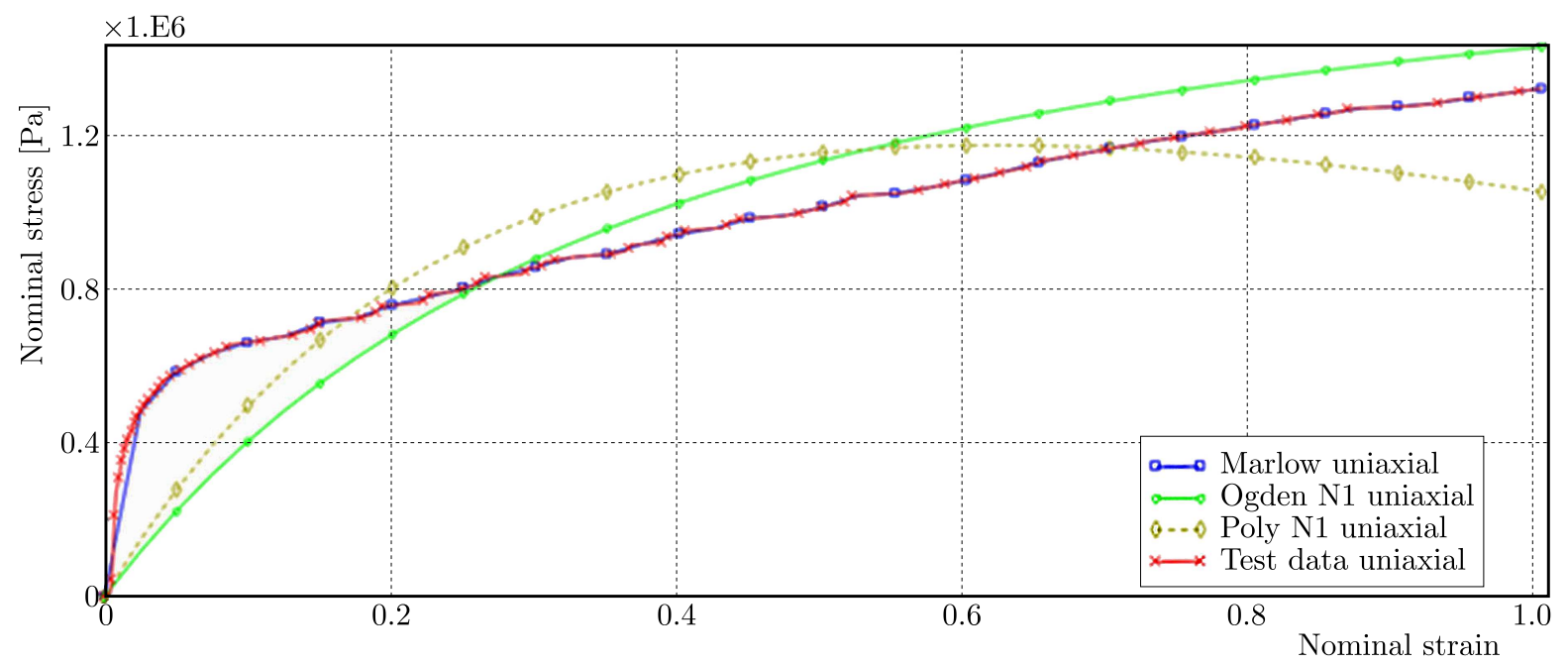

Fig. 5. Evaluation of several hyperelastic models

\subsection{Relaxation test}

Applying the force-time curve (Fig. 4), the normalized shear modulus has been found versus time (Fig. 6).

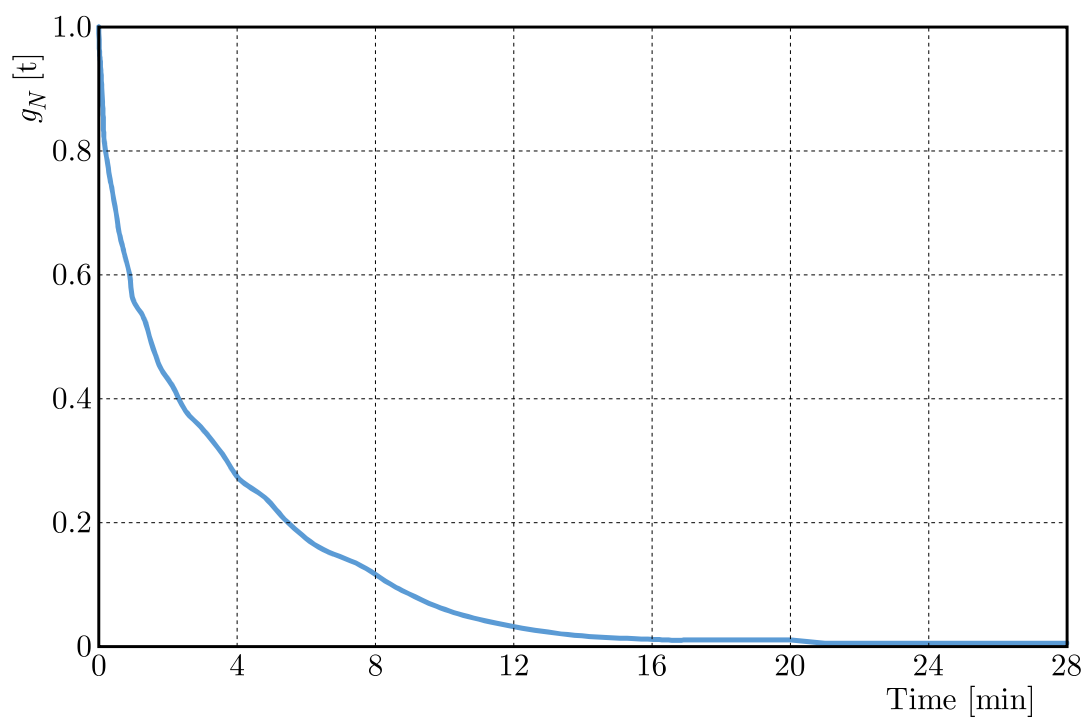

Fig. 6. Normalized shear modulus obtained from relaxation test

Using this curve, constants of the Prony series, Eq. (2.5), were calculated with the help of Matlab software for $N=4$. Table 2 illustrates the magnitude of the constants.

Table 2. Prony series constants for $N=4$

\begin{tabular}{|c|c|c|c|c|c|c|c|}
\hline$g_{1}$ & $g_{2}$ & $g_{3}$ & $g_{4}$ & $\tau_{1}$ & $\tau_{2}$ & $\tau_{3}$ & $\tau_{4}$ \\
\hline \hline 0.151 & 0.67 & 0.16 & 0.013 & 5.144 & 282.8 & 50.26 & 45.93 \\
\hline
\end{tabular}




\section{Finite element model}

The PMMA (Mil-P-8184 grade) free thermoforming process was simulated by ABAQUS software. For this purpose, an axisymmetric model was created (Fig. 7). Diameter of the plate was $280 \mathrm{~mm}$ and two thicknesses were considered: $2.5 \mathrm{~mm}$ and $6.3 \mathrm{~mm}$. According Fig. 7, uniform pressure was applied to the bottom of the surface.

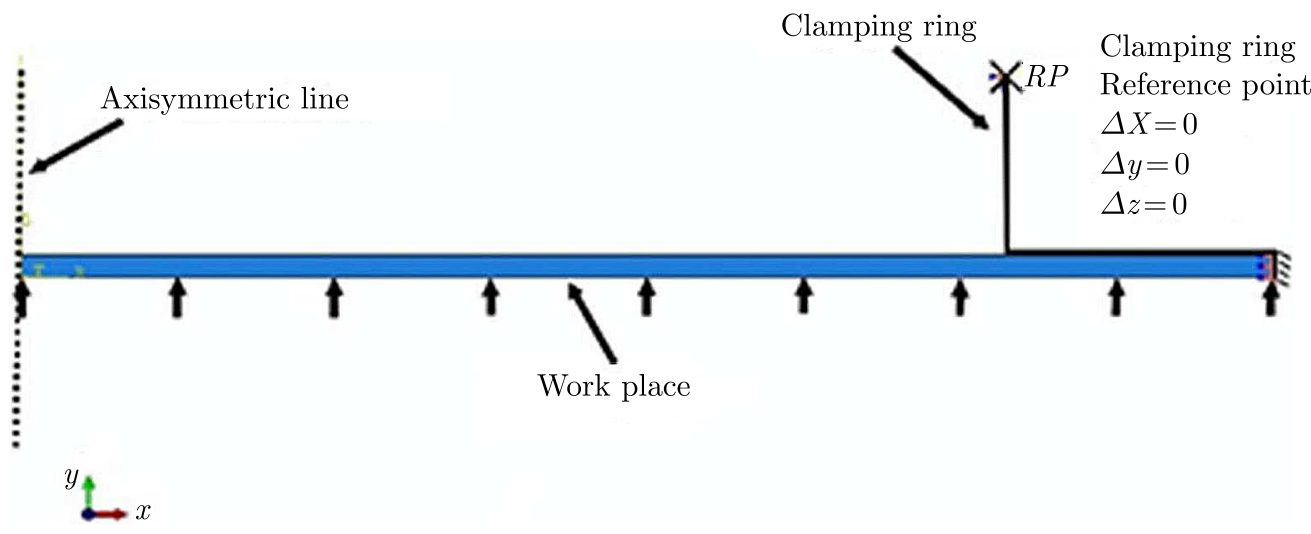

Fig. 7. Finite element model

In the mesh convergence analysis (Table 3), the size of the mesh was $0.0008 \mathrm{~mm}$.

Table 3. Analysis of mesh convergence

\begin{tabular}{|c|c|}
\hline Size of mesh $[\mathrm{mm}]$ & Maximum deflection $[\mathrm{mm}]$ \\
\hline \hline 0.0015 & $5.18 \mathrm{e}-2$ \\
\hline 0.0012 & $5.26 \mathrm{e}-2$ \\
\hline 0.0010 & $5.28 \mathrm{e}-2$ \\
\hline 0.0008 & $5.35 \mathrm{e}-2$ \\
\hline 0.0006 & $5.35 \mathrm{e}-2$ \\
\hline
\end{tabular}

\section{Experimental procedure}

To achieve the real material property of PMMA (Mil-P-8184 grade) during free thermoforming at $160^{\circ} \mathrm{C}$, some experimental tests were carried out.

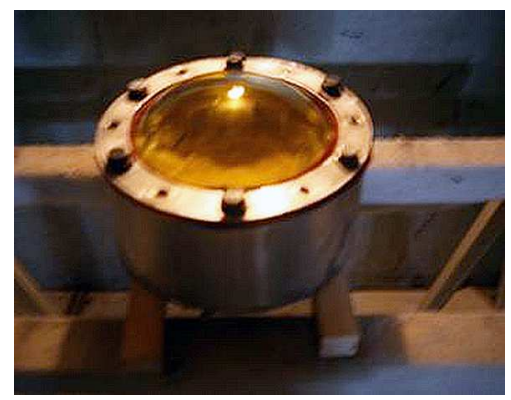

Fig. 8. Deformed plate during free thermoforming

An aluminum circular mold was prepared. Under the mold, a hole was created for exerting air pressure. The plate was cut and then it was drilled. The plate was clamped using a circular ring including bolts and nuts. A silicon gasket between the plate and ring was used for sealing. After 
clamping the plate on the mold, the set was put in oven at $160^{\circ} \mathrm{C}$. When the plate temperature reached $140^{\circ} \mathrm{C}$ and thermal stability was obtained, air pressure was applied. Figure 8 shows the deformed plate after cooling.

\section{Comparison of the experimental tests and numerical results}

For identification of the best mechanical property for simulation of the process, in this Section four experimental tests are compared with the numerical results. In each case, four material types have been considered: three hyperelastic models and one hyperviscoelastic model, for finite element solution. Then maximum deflection and minimum thickness of the deformed plate have been compared with the experimental test. The comparison has been done for three thin plates (thickness/diameter less than 1/20) and one thick plate (thickness/diameter more than $1 / 20)$.

The results are illustrated in Tables 4-7. The comparison between the finite element simulation and the experimental test for the fourth sample is shown in Figs. 9 and 10.

Table 4. Comparison between the simulation results and the experimental test for sample 1 (diameter: $280 \mathrm{~mm}$, initial thickness: $2.5 \mathrm{~mm}$, applied pressure: $0.22 \mathrm{bar}$ )

\begin{tabular}{|l|c|c|c|c|}
\hline & $\begin{array}{c}\text { Minimum thickness } \\
{[\mathrm{mm}]}\end{array}$ & $\begin{array}{c}\text { Maximum deflection } \\
{[\mathrm{mm}]}\end{array}$ & $\mathcal{A}$ & $\mathcal{B}$ \\
\hline \hline Experimental test & 2.05 & 50.4 & - & - \\
\hline $\begin{array}{l}\text { Mooney-Rivlin } \\
\text { hyperelastic model }\end{array}$ & 2.22 & 41.5 & 8.2 & 17.6 \\
\hline $\begin{array}{l}\text { Ogden hyperelastic } \\
\text { model }\end{array}$ & 2.16 & 45 & 5.3 & 10.7 \\
\hline $\begin{array}{l}\text { Marlow } \\
\text { hyperelastic model }\end{array}$ & 2.09 & 52.8 & 1.9 & 4.7 \\
\hline $\begin{array}{l}\text { Hyperviscoelastic } \\
\text { model }\end{array}$ & 2.5 & 11.1 & 21.9 & 77.9 \\
\hline
\end{tabular}

$\mathcal{A}$ - Difference of minimum thickness between simulation and experimental test [\%] $\mathcal{B}$ - Difference of maximum deflection between simulation and experimental test [\%]

Table 5. Comparison between the simulation results and the experimental test for sample 2 (diameter: $280 \mathrm{~mm}$, initial thickness: $2.5 \mathrm{~mm}$, applied pressure: $0.27 \mathrm{bar}$ )

\begin{tabular}{|l|c|c|c|c|}
\hline & $\begin{array}{c}\text { Minimum thickness } \\
{[\mathrm{mm}]}\end{array}$ & $\begin{array}{c}\text { Maximum deflection } \\
{[\mathrm{mm}]}\end{array}$ & $\mathcal{A}$ & $\mathcal{B}$ \\
\hline \hline Experimental test & 1.75 & 65.4 & - & - \\
\hline $\begin{array}{l}\text { Mooney-Rivlin } \\
\text { hyperelastic model }\end{array}$ & 2.36 & 44.1 & 34.8 & 32.5 \\
\hline $\begin{array}{l}\text { Ogden hyperelastic } \\
\text { model }\end{array}$ & 2.27 & 47.9 & 29.7 & 26.7 \\
\hline $\begin{array}{l}\text { Marlow } \\
\text { hyperelastic model }\end{array}$ & 1.85 & 61.1 & 5.7 & 6.5 \\
\hline $\begin{array}{l}\text { Hyperviscoelastic } \\
\text { model }\end{array}$ & 2.5 & 11.9 & 42.8 & 81.8 \\
\hline
\end{tabular}

$\mathcal{A}$ - Difference of minimum thickness between simulation and experimental test [\%] $\mathcal{B}$ - Difference of maximum deflection between simulation and experimental test [\%] 
Table 6. Comparison between simulation results and experimental test for sample 3 (diameter: $280 \mathrm{~mm}$, initial thickness: $2.5 \mathrm{~mm}$, applied pressure: 0.33 bar)

\begin{tabular}{|l|c|c|c|c|}
\hline & $\begin{array}{c}\text { Minimum thickness } \\
{[\mathrm{mm}]}\end{array}$ & $\begin{array}{c}\text { Maximum deflection } \\
{[\mathrm{mm}]}\end{array}$ & $\mathcal{A}$ & $\mathcal{B}$ \\
\hline \hline Experimental test & 1.45 & 85.5 & - & - \\
\hline $\begin{array}{l}\text { Mooney-Rivlin } \\
\text { hyperelastic model }\end{array}$ & 2.3 & 46.9 & 58.6 & 45.1 \\
\hline $\begin{array}{l}\text { Ogden hyperelastic } \\
\text { model }\end{array}$ & 2.24 & 51.6 & 54.5 & 39.6 \\
\hline $\begin{array}{l}\text { Marlow } \\
\text { hyperelastic model }\end{array}$ & 1.54 & 83.1 & 6.2 & 2.8 \\
\hline $\begin{array}{l}\text { Hyperviscoelastic } \\
\text { model }\end{array}$ & 2.5 & 12.7 & 72.4 & 85 \\
\hline
\end{tabular}

$\mathcal{A}$ - Difference of minimum thickness between simulation and experimental test [\%] $\mathcal{B}$ - Difference of maximum deflection between simulation and experimental test [\%]

Table 7. Comparison between the simulation results and the experimental test for sample 4 (diameter: $280 \mathrm{~mm}$, initial thickness: $6.3 \mathrm{~mm}$, applied pressure: $0.6 \mathrm{bar}$ )

\begin{tabular}{|l|c|c|c|c|}
\hline & $\begin{array}{c}\text { Minimum thickness } \\
{[\mathrm{mm}]}\end{array}$ & $\begin{array}{c}\text { Maximum deflection } \\
{[\mathrm{mm}]}\end{array}$ & $\mathcal{A}$ & $\mathcal{B}$ \\
\hline \hline Experimental test & 4.62 & 58.65 & - & - \\
\hline $\begin{array}{l}\text { Mooney-Rivlin } \\
\text { hyperelastic model }\end{array}$ & 5.6 & 44.4 & 21.2 & 24.3 \\
\hline $\begin{array}{l}\text { Ogden hyperelastic } \\
\text { model }\end{array}$ & 5.42 & 49.3 & 17.3 & 15.9 \\
\hline $\begin{array}{l}\text { Marlow } \\
\text { hyperelastic model }\end{array}$ & 4.9 & 57.4 & 6 & 2.1 \\
\hline $\begin{array}{l}\text { Hyperviscoelastic } \\
\text { model }\end{array}$ & 6.35 & 8.7 & 37.4 & 85.1 \\
\hline
\end{tabular}

$\mathcal{A}$ - Difference of minimum thickness between simulation and experimental test [\%] $\mathcal{B}$ - Difference of maximum deflection between simulation and experimental test [\%]

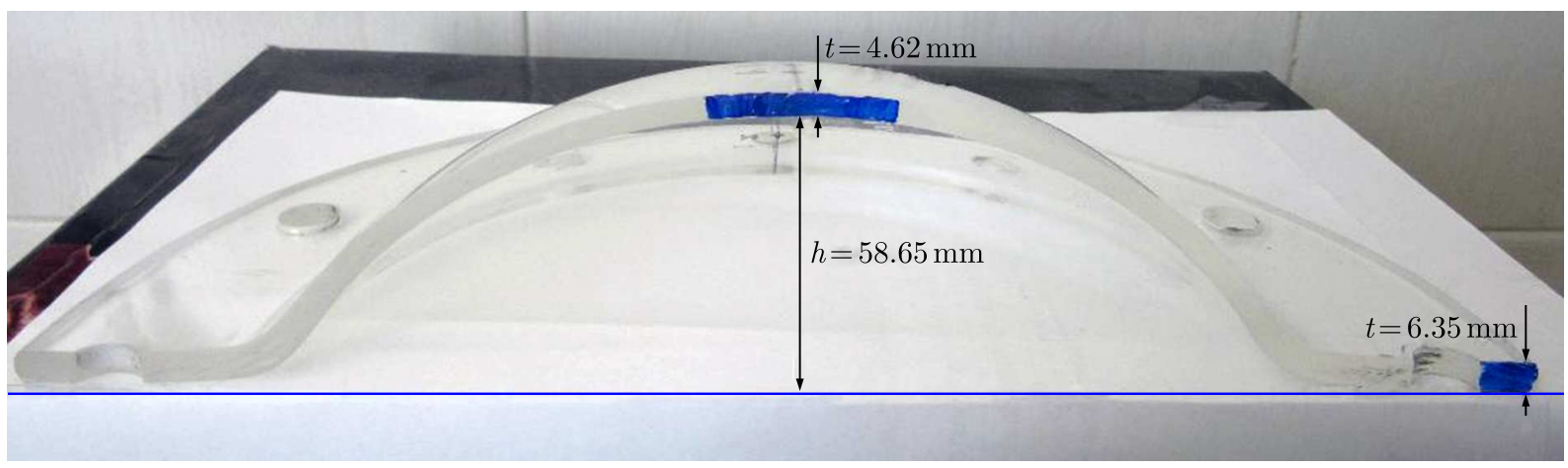

Fig. 9. Deformed plate under 0.6 bar pressure (initial thickness is $6.3 \mathrm{~mm}$ ), sample 4

For the maximum deflection case, the percentage error of all models has been illustrated in Fig. 11.

Also, for the minimum thickness case, the percentage error of all models has been illustrated in Fig. 12. 
(a)

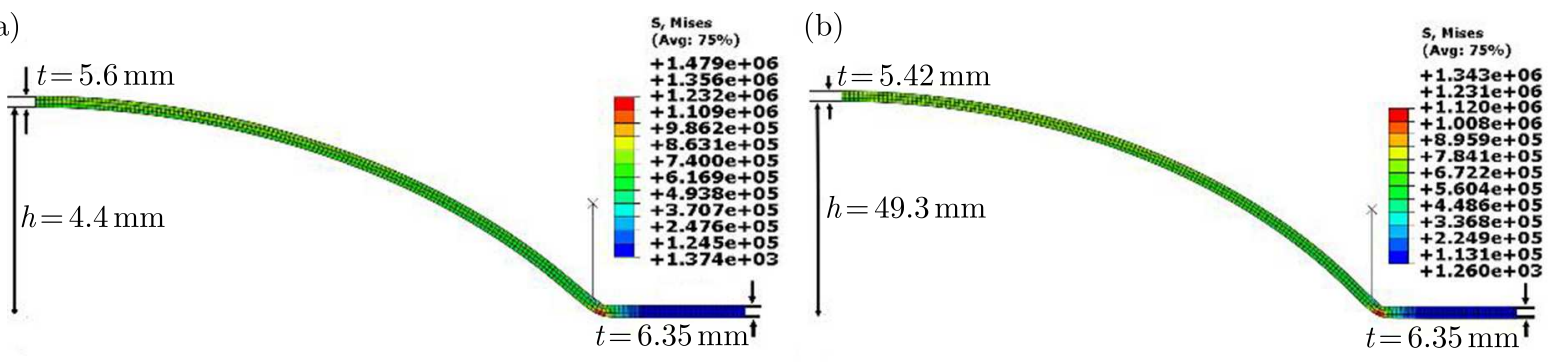

(c) $\mathfrak{t} t=4.9 \mathrm{~mm}$ S, Mises
(Avg: $75 \%$ )

(d)
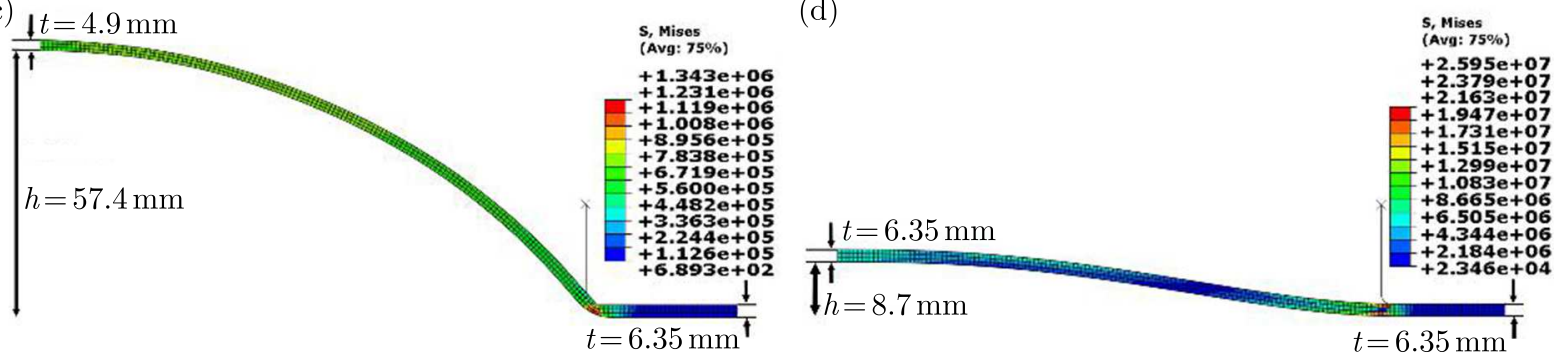

Fig. 10. Simulation results of sample 4: (a) Mooney-Rivlin hyperelastic model, (b) Ogden hyperelastic model, (c) Marlow hyperelastic model, (d) hyperviscoelastic model, sample 4

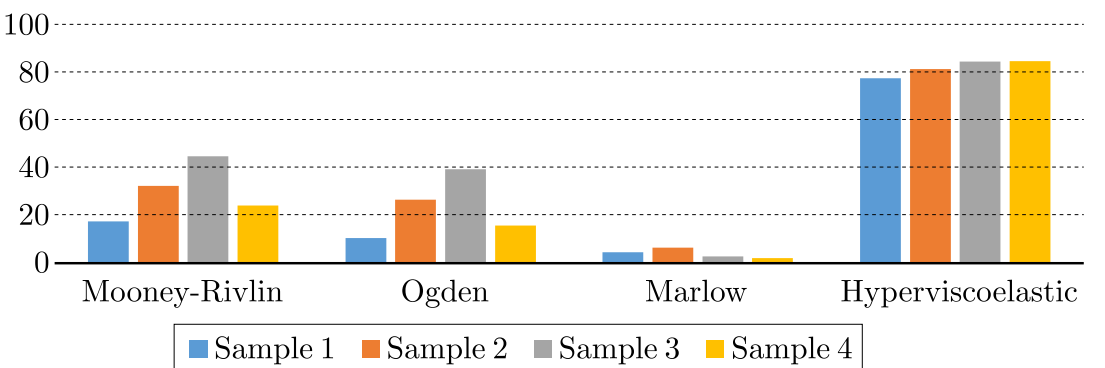

Fig. 11. Comparison of the percentage error of the models in the maximum deflection case

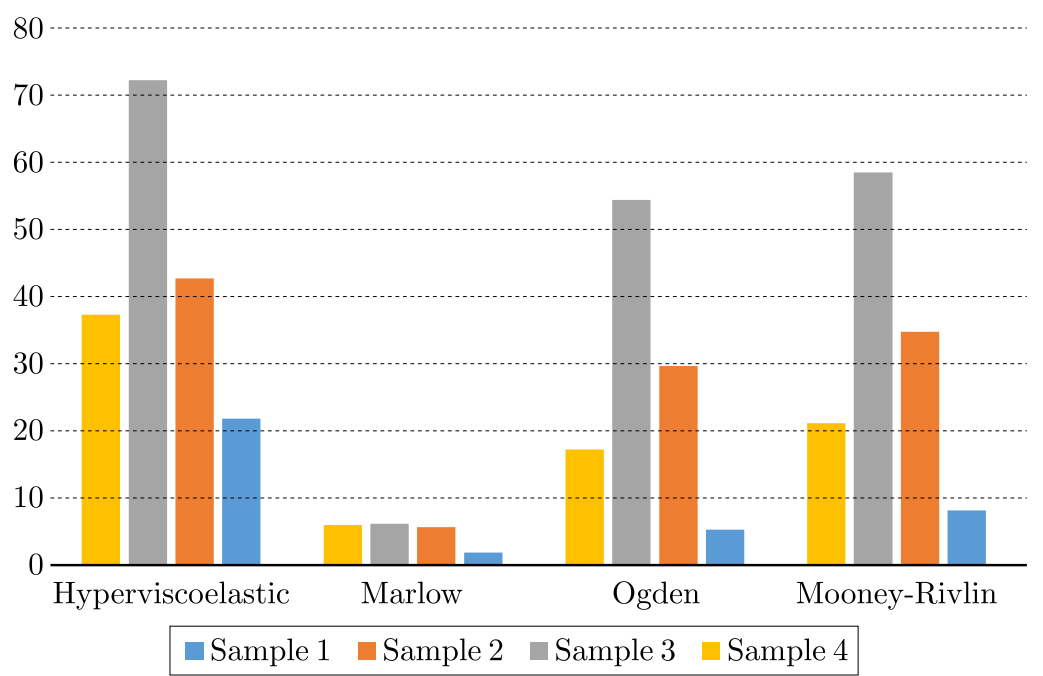

Fig. 12. Comparison of the percentage error of the models in the minimum thickness case

According to Tables 4-7 and Figs. 11 and 12, the Marlow model is the best model for simulation of this process. The mMaximum error for this model is less than 10\%. Among the Ogden and Mooney-Rivlin hyperelastic models, the Ogden model is better, but the percentage error of this model is still high in comparison with actual values. 


\section{Maximum workable pressure with respect to initial thickness}

After finding the best model for simulation of PMMA free thermoforming at $160^{\circ} \mathrm{C}$, another purpose of this paper is finding the maximum pressure that can be exerted on a plate with specified initial thickness. For this study, maximum pressure has been obtained for the specified thickness such that the maximum stress reached $1.8 \mathrm{MPa}$ (maximum allowable stress for PMMA at $160^{\circ} \mathrm{C}$ ). For simulation of the process, the best model (hyperelastic Marlow model) has been used. The simulation has been done for very thin up to thick plates.

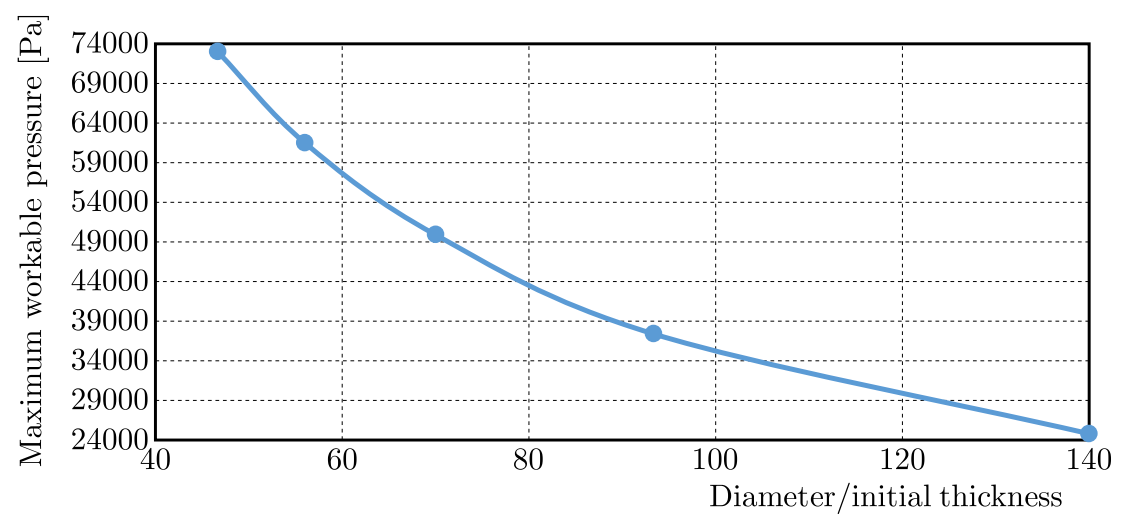

Fig. 13. Maximum workable air pressure versus initial thickness

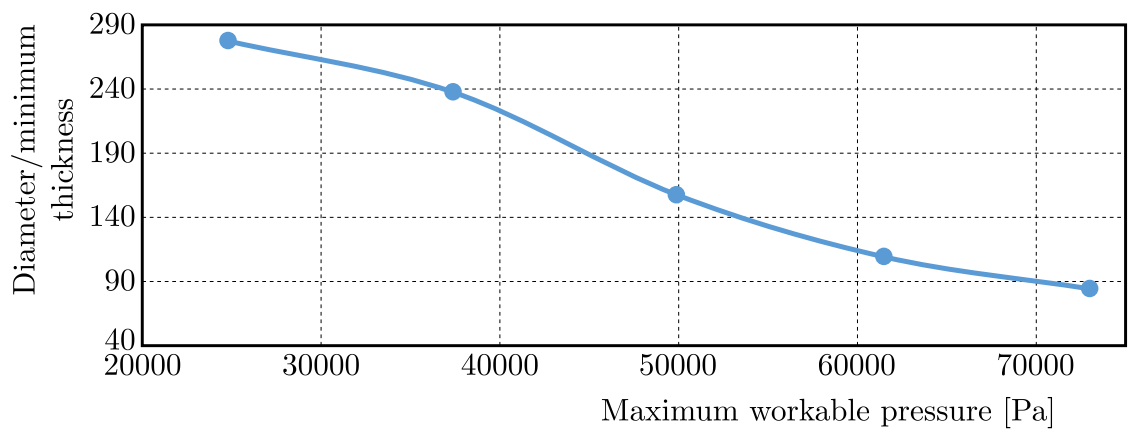

Fig. 14. Minimum thickness of the deformed plate under the maximum workable air pressure

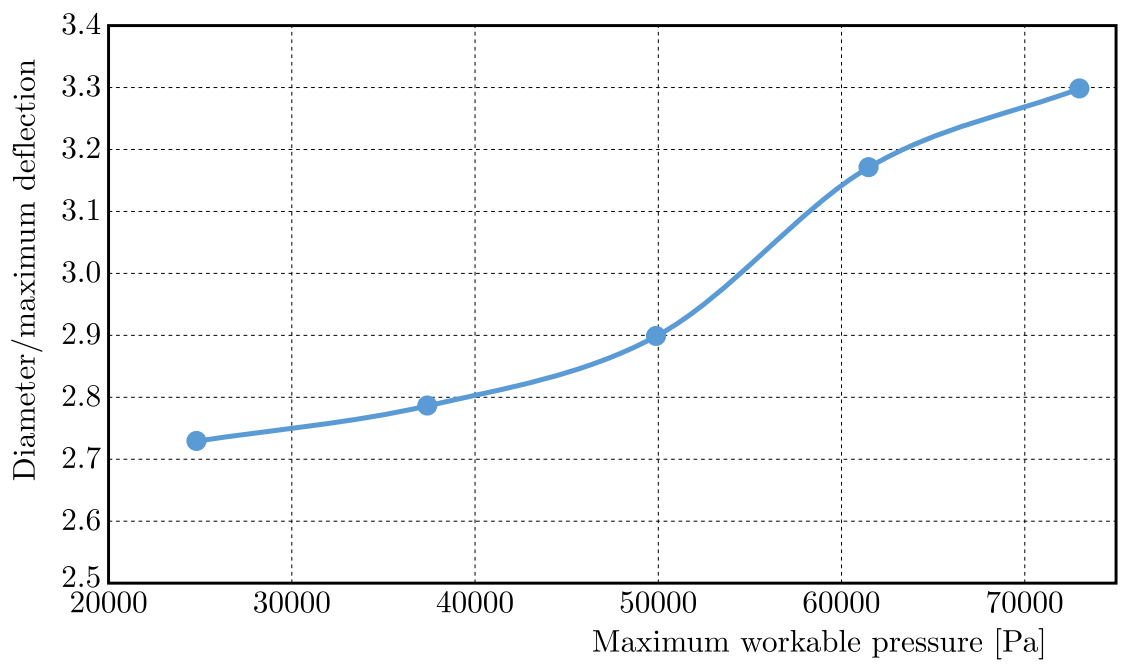

Fig. 15. Maximum deflection of the deformed plate under the maximum workable air pressure

According to this analysis, the maximum workable pressure with respect to initial thickness was obtained according to Fig. 13. Also the maximum deflection and the minimum thickness of the deformed plate, under maximum workable pressure, is shown in Figs. 14 and 15. 
Since an experimental test of PMMA free thermoforming is expensive, these graphs give very good visualization for decision about allowable pressure that can be exerted on a plate with specified thickness, and also maximum deflection and minimum thickness of the deformed plate are predictable.

\section{Conclusion}

PMMA is a flexible material with high impact strength and excellent optical transparency. Thus, this material is being widely used in the related industries. Proper simulation is related to the fact that the material property is defined correctly. In this paper, free thermoforming of PMMA (Mil-P-8184 grade) is investigated at $160^{\circ} \mathrm{C}$. Three hyperelastic models and a hyperviscoelastic model have been selected for simulation. By comparing experimental tests and finite element models, it can be found that the Marlow hyperelastic model is the best model for simulation of this process. Although related to temperature and rate of deformation, the material property of PMMA can be changed between two types of ideal behavior: elastic and viscous, but for free thermoforming of PMMA in $160^{\circ} \mathrm{C}$, hyperviscoelasticity is not appropriate. Between the Ogden and Mooney-Rivlin hyperelastic models, the Ogden model is better, but the percentage error of this model is still high in comparison with actual values. After finding the best model for simulation, the maximum workable air pressure was found. The obtained result is very useful since it prevents from unnecessary expensive experimental tests and visualizes the range of maximum workable air pressure and reachable minimum thickness as well as the maximum deflection.

\section{References}

1. Alexander H., 1968, A constitutive relation for rubber-like materials, International Journal of Engineering Science, 6, 9, 549-563, DOI: 10.1016/0020-7225(68)90006-2

2. Alobaidani A.D., Furniss D., Johnson M.S., Endruweit A., Seddon A.B., 2010, Optical transmission of PMMA optical fibres exposed to high intensity UVA and visible blue light, Optics and Lasers in Engineering, 48, 5, 575-582, DOI: 10.1016/j.optlaseng.2009.11.012

3. Azdast T., Doniavi A., Ahmadi S.R., 2013, Numerical and experimental analysis of wall thickness variation of a hemispherical PMMA sheet in thermoforming process, International Journal of Advanced Manufacturing Technology, 64, 113-122

4. Bagherzadeh S., Biglari F.R., Nikbin K., 2010, Parameter study of stretch-blow moulding process of polyethylene terephthalate bottles using finite element simulation, Proceedings of the Institution of Mechanical Engineers, Part B: Journal of Engineering Manufacture, 224, 8, 1217-1227, DOI: 10.1243/09544054JEM1853

5. Bourgin P., Cormeau I., Saint-Matin T., 1995, A first step towards the modelling of the thermoforming of plastic sheets, Journal of Materials Processing Technology, 54, 1-4, 111, DOI: 10.1016/0924-0136(95)01910-3

6. D-638 Standard Test Method for Tensile Properties of Plastics, ASTM, United States, 2004

7. Dong Y., Lin R.J.T., Bhattacharyya D., 2005, Determination of critical material parameters for numerical simulation of acrylic sheet forming, Journal of Materials Science, 40, 399-410

8. Dong Y., Lin R.J.T., Bhattacharyya D., 2006, Finite element eimulation on thermoforming acrylic sheets using dynamic explicit method, Polymers and Polymer Composites, 14, 3, 307-328, DOI: $10.1177 / 096739110601400310$

9. Ghoreishy M.H.R., 2012, Determination of the parameters of the Prony series in hyper-viscoelastic material models using the finite element method, Materials and Design, 35, 791-797, DOI: $10.1016 /$ j.matdes.2011.05.057 
10. Guo Z., Sluys L.J., 2006, Application of a new constitutive model for the description of rubber-like materials under monotonic loading, International Journal of Solids and Structures, 43, 9, 2799-2819, DOI: 10.1016/j.ijsolstr.2005.06.026

11. Han P., Butterfield J., Buchanan S., McCool R., Jiang Z., Price M., Murphy A., 2013, The prediction of process-induced deformation in a thermoplastic composite in support of manufacturing simulation, Proceedings of the Institution of Mechanical Engineers, Part B: Journal of Engineering Manufacture, 227, 10, 1417-1429, DOI: 10.1177/0954405413488362

12. Mahl M., Jelich C., Baier H., 2016, Thermo-mechanical behavior of polyethylene under mechanical loads at cryogenic and elevated temperatures, International Journal of Pressure Vessels and Piping, 150, 11-18, DOI: 10.1016/j.ijpvp.2016.12.007

13. Marques S.P., Creus G.J., 2012, Solution with Abaqus, [In:] Computational Viscoelasticity, Springer Briefs in Applied Sciences and Technology, Springer, Berlin, Heidelberg, 103111

14. Meissner J., 1987, Polymer melt elongation - methods, results, and recent developments, Polymer Engineering and Science, 27, 8, 537-546, DOI: 10.1002/pen.760270802

15. Meissner J., Raible T., Stephenson S.E., 1981, Rotary clamp in uniaxial and biaxial extensional rheometry of polymer melts, Journal of Rheology, 25, 1, DOI: 10.1122/1.549635

16. Milani G., Milani F., 2012, Stretch-stress behavior of elastomeric seismic isolators with different rubber materials: numerical insight, Journal of Engineering Mechanics (ASCE), 138, 5, DOI: 10.1061/(ASCE)EM.1943-7889.0000340

17. Ramezani M., Ripin Z.M., Ahmad R., Akil H.M., Damghani-Nouri M., 2010, High strain-rate bulge forming of sheet metals using a solid bulging medium, Proceedings of the Institution of Mechanical Engineers, Part B: Journal of Engineering Manufacture, 224, 2, 257-270, DOI: 10.1243/09544054JEM1550

18. Schmidt L.R., CARley J.F., 1975a, Biaxial stretching of heat-softened plastic sheets: Experiments and results, Polymer Engineering and Science, 15, 51, DOI: 10.1002/pen.760150109

19. Schmidt L.R., CARley J.F., 1975b, Biaxial stretching of heat-softened plastic sheets using an inflation technique, International Journal of Engineering Science, 13, 6, 563-578, DOI: 10.1016/00207225(75)90091-9

20. Shapourgan O., Faraji G., 2016, Rubber pad tube straining as a new severe plastic deformation method for thin-walled cylindrical tubes, Proceedings of the Institution of Mechanical Engineers, Part B: Journal of Engineering Manufacture, 230, 10, 1845-1854, DOI: 10.1177/0954405416654185

21. Sharabi M., Varssano D., Eliasy R., Benayahu Y., Benayahu D., Haj-Ali R., 2016, Mechanical flexure behavior of bio-inspired collagen-reinforced thin composites, Composite Structures, 153, 392-400, DOI: 10.1016/j.compstruct.2016.06.031

22. Simulia, Abaqus CAE documentation, Dassault systemes, 2012

23. Throne J.L., 1996, Technology of Thermoforming, Hanser Publishers, Munich

24. Trelon L.R.G., 1958, The Physics of Rubber Elasticity, Oxford University Press, Oxford, UK, p. 78

25. WAng J., Xu Y., Zhang W., 2014, Finite element simulation of PMMA aircraft windshield against bird strike by using a rate and temperature dependent nonlinear viscoelastic constitutive model, Composite Structures, 108, 21-30

26. Williams J.G., 1970, A method of calculation for thermoforming plastics sheets, Journal of Strain Analysis, 5, 1, 49-57, DOI: 10.1243/03093247V051049

27. ZAFOŠNik B., BoŽIČ U., FlorJaniČ B., 2015, Modelling of an analytical equation for predicting maximum stress in an injections moulded undercut geometry during ejection, International Journal of Precision Engineering and Manufacturing, 16, 12, 2499-2507 